Published in final edited form as:

Semin Nephrol. 2016 July ; 36(4): 283-292. doi:10.1016/j.semnephrol.2016.05.005.

\title{
THE ROLE OF ACUTE KIDNEY INJURY IN CHRONIC KIDNEY DISEASE
}

\author{
Raymond K. Hsu, MD, MAS and Chi-yuan Hsu, MD, MSc \\ Division of Nephrology, Department of Medicine, University of California, San Francisco
}

\begin{abstract}
There is increasing recognition that acute kidney injury (AKI) and chronic kidney disease (CKD) are closely linked and likely promote one another. Underlying CKD is now recognized as a clear risk factor for AKI, as both decreased glomerular filtration rate (GFR) and increased proteinuria have each been shown to be strongly associated with AKI. A growing body of literature also provides evidence that AKI accelerates the progression of CKD. Individuals who suffered dialysisrequiring $\mathrm{AKI}$ are particularly vulnerable to worse long-term renal outcomes, including end-stage renal disease (ESRD). The association between AKI and subsequent renal function decline is amplified by pre-existing severity of CKD, higher stage AKI, and cumulative number of AKI episodes. However, residual confounding and ascertainment bias may partly explain the epidemiologic association between AKI and CKD in observational studies. As the number of AKI survivors increases, we need to better understand other clinically important outcomes after AKI, identify those at highest risk for the most adverse sequelae, and develop strategies to optimize their care.
\end{abstract}

\section{Keywords}

acute kidney injury; acute renal failure; chronic kidney disease; epidemiology; outcomes

\section{Introduction}

There have been several important developments in the literature recently regarding the association between acute kidney injury (AKI) and chronic kidney disease (CKD). First, when the National Kidney Foundation promulgated their highly influential Kidney Disease Outcomes Quality Initiative (KDOQI) CKD guidelines in 2002, six chapters were devoted to the complications associated with decreased glomerular filtration rate (GFR) including hypertension, anemia, nutritional status, bone disease/disorders of calcium and phosphorus metabolism, neuropathy, and indices of functioning/well-being. ${ }^{1}$ Notably, AKI was not

Corresponding Author: Chi-yuan Hsu, MD, MSc, 533 Parnassus Avenue, U404, Division of Nephrology, University of California, San Francisco, San Francisco, CA 94143-0532, Phone: 415-476-2172, Fax: 415-476-3381, hsuchi@medicine.ucsf.edu.

Conflict of Interest: The authors declare no conflicts of interest.

Publisher's Disclaimer: This is a PDF file of an unedited manuscript that has been accepted for publication. As a service to our customers we are providing this early version of the manuscript. The manuscript will undergo copyediting, typesetting, and review of the resulting proof before it is published in its final citable form. Please note that during the production process errors may be discovered which could affect the content, and all legal disclaimers that apply to the journal pertain. 
included although it had long been known that patients with CKD were more prone to AKI ("acute on chronic renal failure"). Much of the CKD epidemiology literature around the time of and following the KDOQI CKD guideline publication focused on how reduced (estimated) GFR (and proteinuria) is related to risk of end-stage renal disease, cardiovascular events, and death. ${ }^{2-4}$ Since 2008 , however, a number of papers have sought to better quantify how the severity of CKD is a risk factor for development of AKI. ${ }^{5}$ These are discussed in more detail below (section "CKD as a risk factor for AKI").

Second, recent studies have highlighted the fact that the population incidence of AKI appears to be increasing rapidly ${ }^{6-12}$ Recognizing the sizable and growing public health burden of AKI has focused more attention on its role in the natural history of CKD. ${ }^{13,14}$

Third, there has been a great deal of interest in and investigation into AKI as an instigator and promoter of CKD. Most of this manuscript will be devoted to reviewing the burgeoning literature on this topic. There is now a general consensus that AKI and CKD are, at times, two closely linked and interconnected syndromes. ${ }^{13,15,16}$

\section{CKD as a risk factor for AKI}

The association between severity of CKD (e.g., as measured by levels of estimated GFR) and risk of AKI has not been quantified until relatively recently. In 2008, Hsu et al. compared 1,746 hospitalized adult members of an integrated health care delivery system (Kaiser Permanente Northern California) who developed dialysis-requiring AKI with 600,820 hospitalized members who did not, and showed that the adjusted odds ratios were significantly and progressively elevated from 2.0 (95\% CI 1.7-2.3) for those with baseline eGFR $45-59 \mathrm{ml} / \mathrm{min} / 1.73 \mathrm{~m}^{2}$ up to 40.1 (95\% CI 33.8-47.6) for those with baseline eGFR $<15 \mathrm{ml} / \mathrm{min} / 1.73 \mathrm{~m}^{2}$, when compared to referent patients with baseline eGFR $\geq 60 \mathrm{ml} / \mathrm{min} /$ $1.73 \mathrm{~m}^{2.5}$ This paper was also the first to report that proteinuria was a strong risk factor for AKI (adjusted odds ratio 2.8 [95\% CI 2.5-3.1] for dipstick proteinuria $1+$ or greater). ${ }^{5}$

The latter association - that proteinuria is a risk factor for AKI--had not previously been appreciated, but has since been confirmed in a number of subsequent publications. ${ }^{17}$ These studies advanced the field by quantifying proteinuria closer in time to the event precipitating AKI (e.g., cardiac surgery ${ }^{18}$ ), by more precisely quantifying proteinuria down into the microalbuminuria range ${ }^{19}$ and by examining other community-based populations. ${ }^{20} \mathrm{~A}$ number of meta-analyses have now been published characterizing how AKI risk is independently determined by severity of CKD—defined on two orthogonal dimensionsestimated GFR and albuminuria ${ }^{21}$ (Figure 1) and describing how associations may vary in important subgroups. ${ }^{22,23}$

Why is CKD a risk factor for AKI? Certainly some of the connection is biological, related to diseased kidneys' reduced renal reserve and inability to handle stress such as abnormally low blood pressure or nephrotoxic drugs. However, the exact pathophysiological relationship between CKD and AKI is not well understood. In fact, some animal studies have suggested that prior renal injury actually conferred protection against subsequent insults to the kidney ("preconditioning"). ${ }^{24}$ An alternative (or additional) reason for the association between 
CKD and subsequent AKI may be that patients with CKD experience more acute medical illnesses requiring hospitalizations and procedures that increase the risk of exposure to nephrotoxic insults. Although attempts have been made in prior studies to adjust for such AKI risk factors (such as hyperbilirubinemia, intensive care unit stay, sepsis, mechanical ventilation, cardiac surgery, and cardiac catheterization), ${ }^{5}$ it is difficult to completely eliminate the role of residual confounding when examining CKD as a risk factor for AKI. Finally, due to the reciprocal mathematical relationship between GFR and serum creatinine level $(\mathrm{Cr})$, with any given absolute decrement of GFR (e.g., $30 \mathrm{ml} / \mathrm{min} / 1.73 \mathrm{~m}^{2}$ ) the increment in $\mathrm{Cr}$ (in $\mathrm{mg} / \mathrm{dl}$ ) will be greater if GFR is lower (i.e., serum $\mathrm{Cr}$ is higher) at baseline, hence making it easier for patients with CKD to fulfill any AKI definition that is based on changes in serum $\mathrm{Cr}$ level (e.g., $0.3 \mathrm{mg} / \mathrm{dl}$ per either the Acute Kidney Injury Network $[\mathrm{AKIN}]^{25}$ or Kidney Disease Improving Global Outcomes $[\mathrm{KDIGO}]^{26}$ guidelines). The same argument holds for the outcome of dialysis-requiring AKI, since with any given acute absolute decrement in GFR, a patient starting at a lower GFR (e.g. $25 \mathrm{ml} / \mathrm{min} / 1.73 \mathrm{~m}^{2}$ ) prior to AKI would be more likely to reach the threshold for starting dialysis than a patient starting at a higher GFR (e.g. $85 \mathrm{ml} / \mathrm{min} / 1.73 \mathrm{~m}^{2}$ ). However, it is doubtful that this final possibility is the only (or primary) explanation since proteinuria-independent of level of GFR—is also a risk factor for AKI.

The more frequent occurrence of AKI with greater severity of CKD complicates our ability to explore if AKI is a risk factor for CKD. In other words, an association observed between $\mathrm{AKI}$ and a subsequent more rapid decline in renal function may not be due to AKI's causing the more rapid decline, but rather, due to AKI being a marker that identifies higher risk CKD patients more likely to progress rapidly (e.g., because they have higher levels of baseline proteinuria).

\section{AKI as an accelerator of the progression of CKD}

For several decades, many physicians believed that AKI was a self-limited process followed by complete recovery of kidney function to pre-AKI levels among survivors. (Numerous trainees have been taught some variant of the old adage: "If the patients survive, so will their kidneys.") But this view has been challenged by an increasing number of studies demonstrating that AKI can initiate the development of or accelerate the progression of CKD. ${ }^{15,16,27,28}$ Animal models of AKI have shed light on potential mechanisms of maladaptive repair after AKI, characterized by fibrosis, vascular rarefaction, tubular loss, glomerulosclerosis, and chronic interstitial inflammation-resulting in a state that mimics accelerated kidney aging and hence functional decline. ${ }^{29-32}$ There is now general acceptance of the notion that AKI accelerates progression of CKD and is an important mechanism of CKD progression (although acceptance is not universal-please see section below regarding "Controversies and unresolved issues"). Some have even written that "Identification of the AKI-CKD nexus represents the single most important advance in understanding of the mechanisms of progression since hyperfiltration was shown to occur following renal ablation and chronic nephropathy." 32

An important reason for the lack of appreciation of the long-term impact of AKI is that, traditionally, clinical studies of AKI have focused on in-hospital outcomes--such as short- 
term mortality and resource utilization ${ }^{33-36}$ —and did not have follow-up information on what transpired months to years after hospital discharge. Hence the association between AKI and subsequent changes in renal function among those with CKD could not be studied.

Contemporary literature on the long-term sequelae of AKI, including the impact of AKI on renal trajectory, dates back to around 2008, when two papers were published on the longterm outcomes associated with AKI within a cohort of Medicare (age 65 years or older) patients who had acute myocardial infarctions. ${ }^{37,38} \mathrm{AKI}$ was found to have an independent and graded association with both progression to end-stage renal disease (ESRD) ${ }^{37}$ (and allcause mortality ${ }^{38}$ ) over a decade of follow-up.

Subsequently, a growing number of studies have linked AKI with development and acceleration of CKD. The early literature, which established the field has been wellsummarized in a meta-analysis by Coca et al. ${ }^{39}$ Table 1 lists the patient characteristics from the thirteen cohort studies ${ }^{20,37,40-51}$ included in that systematic review. Eleven of the thirteen studies followed more than 3,000 patients each, and all were retrospective. One study included patients with HIV exclusively, ${ }^{42}$ and two studies included recipients of hematopoietic stem cell transplants. ${ }^{43,48}$ Overall, patients who experienced AKI (compared to those without AKI) had an almost 9-fold higher adjusted risk of CKD (pooled adjusted hazard ratio [HR] 8.8, 95\% CI 3.1-25.5) and a 3-fold higher adjusted risk of progressing to ESRD (pooled adjusted HR 3.1, 95\% CI 1.9-5.0)(Figure 2). ${ }^{39}$ Furthermore, the relationship between AKI and CKD or ESRD was graded, with larger risk associated with greater severity of AKI.

In the following sections, we highlight a number of key studies, including some published after this systematic review.

\section{Studies focusing on dialysis-requiring AKI}

Among the studies linking AKI with CKD progression, only a few focused exclusively on the most severe form of AKI—cases that required dialysis ${ }^{40,41,46}$ (we use the term "dialysis" to capture all modalities of acute renal replacement therapy including continuous renal replacement therapy or intermittent hemodialysis). Using data from a large integrated healthcare delivery system in Northern California, Lo et al. studied patients who had baseline estimated GFR $\geq 45 \mathrm{ml} / \mathrm{min} / 1.73 \mathrm{~m}^{2}$ and who experienced dialysis-requiring AKI, and recovered from dialysis-dependency by 30 days post-discharge. These investigators found that dialysis-requiring AKI was associated with a 28 -fold increase in risk of developing stage 4 or higher CKD (adjusted HR 28.1; 95\% CI 21.1-37.6). ${ }^{41}$ The same research group studied patients with known CKD at baseline (estimated GFR $<45 \mathrm{ml} / \mathrm{min} /$ $1.73 \mathrm{~m}^{2}$ ) and found that patients with "acute on chronic renal failure" had an adjusted $47 \%$ increased risk of ESRD within 30 days of discharge, compared to hospitalized CKD patients without AKI. ${ }^{40}$

Inferences from these studies are powerful because it is more plausible that a serious injury (e.g., one requiring acute dialysis) causes long-term permanent kidney damage. In contrast, mild or rapidly reversible acute changes in renal function (such as "pre-renal azotemia," which has historically been considered a functional and not a structural disorder), are less 
likely to cause long-term renal parenchymal damage. Accordingly, their associations with adverse outcomes are likely explained by residual confounding due to shared risk factors. ${ }^{52}$ Another strength of studies focusing on dialysis-requiring AKI is that misclassification of $\mathrm{AKI}$ is less likely. In contrast, use of small changes in serum $\mathrm{Cr}$ to diagnose AKI is associated with high false-positive rates caused by inherent variability of serum $\mathrm{Cr}$ (particularly a problem at higher baseline values, potentially misclassifying patients with CKD in AKI studies). ${ }^{53}$

\section{Studies of AKI and progression of CKD with more rigorous quantification of pre-AKI eGFR levels}

Owing to the availability of comprehensive clinical data from the same Northern California integrated health system, the above two referenced studies also had excellent assessments of baseline kidney function. ${ }^{40,41}$ Reliable assessment of baseline renal function is important in this situation for several reasons. First, it allows for better control of potential confounding because baseline CKD severity is a very strong risk factor for AKI (section above "CKD as a risk factor for AKI"). Second, reliable assessment of baseline renal function allows for better quantification of the degree of renal function loss associated with AKI. In both studies, ${ }^{40,41}$ the investigators identified the last outpatient estimated GFR before hospitalization, as inpatient creatinine measurements may not reflect baseline kidney function. Sensitivity analyses that used outpatient serum creatinine measurements greater than 30 days prior to admission to reduce the possibility that the last observed outpatient creatinine value reflected acute illness/community-acquired AKI showed results similar to the main study analysis. This pair of studies also allowed for direct comparisons of "de-novo AKI" (AKI in a patient without baseline CKD) vs. "acute on chronic renal disease" due to well-defined baseline kidney function assessment. Notably, the risk of non-recovery from dialysis dependency (i.e., immediate precipitation of ESRD) varied with level of baseline renal function—being $84 \%$ among survivors with baseline estimated GFR $\_45 \mathrm{ml} / \mathrm{min} / 1.73 \mathrm{~m}^{2}, 58 \%$ among survivors with baseline estimated GFR $30-44 \mathrm{ml} / \mathrm{min} / 1.73 \mathrm{~m}^{2}$, and $37 \%$ among survivors with baseline estimated GFR $15-29 \mathrm{ml} / \mathrm{min} / 1.73 \mathrm{~m}^{2.40,41}$

Another study greatly strengthened by having quantification of pre-AKI estimated GFR levels for comparison with subsequent estimated GFR evolution comes from Amdur et al. who leveraged the comprehensive clinical information from the U.S. Veterans Affairs database-another integrated healthcare delivery system..$^{51}$ They found that patients with AKI, especially those diagnosed with acute tubular necrosis (ATN), were more likely than controls (who were hospitalized without acute myocardial infarction or pneumonia without AKI) to develop stage 4 CKD or experience the composite outcome of death, ESRD or stage $4 \mathrm{CKD}$.

\section{Effect of baseline proteinuria on the association between AKI and subsequent CKD progression}

A key parameter that characterizes the severity of chronic kidney disease in addition to estimated GFR is the level of proteinuria. James et al. utilized a provincial sample of nearly one million adults in Alberta, Canada to study the associations among baseline renal function, proteinuria, and AKI. ${ }^{20}$ While they found that lower baseline estimated GFR and 
higher levels of proteinuria were associated with a greater risk of AKI, they also observed that higher levels of proteinuria predicted the long-term renal composite outcome of ESRD or doubling of serum creatinine, following an episode of AKI (Figure 3). This study has provided important evidence that proteinuria worsens, in an additive and graded manner, the impact of AKI on long-term renal function decline across all levels of baseline estimated GFR. $^{20}$

\section{Effect modification by baseline CKD severity}

Investigators have also refined our understanding of the impact of AKI among CKD patients by examining the modification of AKI's effect by the severity of baseline CKD. Some earlier studies have emphasized that the superimposition of AKI on CKD greatly increases the risk of ESRD (compared with patients who only have AKI or only have CKD) ${ }^{49}$ but the findings were based on diagnoses detected using administrative codes which are known to have important limitations. ${ }^{54-57}$

Studies that used actual serum creatinine measurements to study this problem include that by Wu et al. who conducted a multiple-center study in Taiwan to directly compare "acute on chronic kidney injury" and "de-novo AKI" in intensive care unit (ICU) patients who had undergone major surgery. ${ }^{58}$ The patients with "acute on chronic kidney injury" had a 20 -fold higher risk of long-term dialysis (adjusted HR 19.8, 95\% CI 13.6-28.7), compared to those with AKI without pre-existing CKD. (Long-term mortality was also higher among the "acute on chronic kidney injury" patients.)

Pannu et al. used provincial data from Alberta, Canada and observed that lower levels of baseline estimated GFR and greater severity of AKI both independently increased risk of ESRD. At any given severity of AKI, death was less likely among those with lower baseline estimated GFR. ${ }^{59}$ That "de novo AKI" is associated with higher short-term mortality than acute on chronic kidney injury has been noted also before. ${ }^{40,41,60}$ This observation may at first appear paradoxical, but it may be that in the latter case, a lesser degree of nephrotoxic and systemic insult is required for the patients with CKD to experience superimposed AKI thereby explaining the lower overall mortality rate from AKI in this setting. ${ }^{40}$

\section{Cumulative effect of repeated AKI episodes}

Almost all the aforementioned publications focused on the effect of a single episode of AKI on CKD progression. Thakar et al., however, reported on the effects of AKI episodes during multiple hospitalizations. ${ }^{61}$ These authors studied the impact of AKI on risk of CKD in patients with diabetes mellitus within the U.S. Veterans Affairs healthcare system, and found that not only was AKI (vs. no AKI) associated with a 3.6-fold higher risk of developing stage 4 CKD (adjusted HR 3.6, 95\% CI 2.8-4.6), but also that this risk was additionally doubled with each additional AKI episode (adjusted HR 2.0, 95\% CI 1.8-2.3).

The prevalence of recurrent AKI (defined as a recurrent AKI episode within one year) was reported in a recent study by Siew et al. to be $25 \% .{ }^{62}$ These findings raise the possibility that recurrent episodes of AKI are an important reason for recent observations that reductions in estimated GFR as CKD progresses often take a non-linear trajectory. ${ }^{63-66}$ These patterns of 
renal function decline suggest that kidney disease often does not progress in a linear fashion, which had been a commonly accepted paradigm. ${ }^{67}$

\section{Effect of AKI severity on CKD progression}

Mammen et al. evaluated a pediatric ICU population with AKI for subsequent incident CKD defined as estimated GFR $<60 \mathrm{ml} / \mathrm{min} / 1.73 \mathrm{~m}^{2}$ or albuminuria. ${ }^{68}$ They found that the incidence of CKD over the subsequent 1-3 years increased in a graded manner from 5\% among those who experienced $\mathrm{AKIN}^{25}$ stage $1 \mathrm{AKI}$ (defined as serum $\mathrm{Cr}$ increase by $\geq 50 \%$ or by $\geq 0.3 \mathrm{mg} / \mathrm{dL}$ from baseline) to $17 \%$ among those who experienced AKIN stage 3 AKI (defined as serum $\mathrm{Cr}$ increase to $\geq 3$ times baseline, or increase to $\mathrm{Cr} \geq 4 \mathrm{mg} / \mathrm{dL}$ with an absolute increase by $0.5 \mathrm{mg} / \mathrm{dL}$, or requiring renal replacement therapy). ${ }^{68}$

Chawla et al. used Veterans Affairs patient data to test the hypothesis that severity of AKI is useful to risk stratify progression of $\mathrm{CKD} .{ }^{69}$ Using multivariable logistic regression models, the authors found that each incremental stage in AKI severity - as defined using the Risk, Injury, Failure, Loss, and End-stage Kidney Disease (RIFLE) ${ }^{70}$ criteria—was associated with 4.4-fold higher odds of entering stage 4 or greater CKD (adjusted odds ratio [OR] 4.4, 95\% CI 4.0-4.9). (The authors utilized cutoffs in change in Cr and GFR to stage AKI as per RIFLE critieria, but not urine output.) Furthermore, AKI requiring renal replacement therapy by itself was associated with 53-fold higher odds of entering stage 4 or greater CKD (adjusted OR 53.2, 95\% CI 11.3-250.6). The authors concluded that the extraordinary risk of long-term renal derangement associated with more severe AKI should help guide which patients warrant nephrology follow-up after hospital discharge. ${ }^{69}$

\section{Reversible AKI and CKD}

Bucaloiu et al. used data from a large integrated health system in Central Pennsylvania and found that even reversible AKI is associated with a higher rate of subsequent incident CKD. ${ }^{71}$ Patients with normal kidney function and no proteinuria at baseline who experienced "reversible AKI," defined by return of the serum creatinine to within $90 \%$ of baseline within 90 days of AKI, had a nearly 2-fold increased risk of incident CKD during follow-up compared with matched controls without AKI (adjusted HR 1.9, 95\% CI 1.82.1). ${ }^{71}$

A study by Jones and colleagues also found that AKI with complete recovery (defined as a return of serum creatinine levels to less than 1.1 times baseline values) was significantly associated with development of incident stage $3 \mathrm{CKD} .{ }^{72}$ The authors utilized data from a large integrated health system in Utah, and found that during a median follow-up of 2.5 years, incident stage 3 CKD occurred in $15 \%$ of those with AKI (with recovery), yielding an adjusted HR of 3.8 (95\% CI, 2.8-5.12) when compared with those without AKI). ${ }^{72}$

More recently, Heung et al. analyzed Veterans Affairs data and reported that even KDIGO ${ }^{26}$ Stage 1 AKI with "fast" recovery (defined as return in serum $\mathrm{Cr}$ to within $0.3 \mathrm{mg} / \mathrm{dL}$ of baseline within 2 days from peak serum $\mathrm{Cr}$ ) was independently associated with increased risk for development of CKD (adjusted relative risk ratio 1.4, 95\% CI 1.4-1.5). ${ }^{73}$ 


\section{Controversies and unresolved issues}

The fact that even mild episodes of AKI or rapidly reversible cases (which would be considered "pre-renal azotemia" by many physicians) are independently associated with a future decline in renal function raises the possibility these associations are not indicative of a causal relationship. This concern had been raised early on in this field, ${ }^{74}$ and remains an outstanding issue.

Rifkin and colleagues ${ }^{75}$ have argued that the current literature suffers from several important shortcomings, including residual confounding (due to shared risk factors between AKI and $\mathrm{CKD}$ ) and ascertainment bias (for example, in clinical datasets, sicker patients have more follow-up assessments and thereby have greater opportunity for CKD to be detected and detected sooner). ${ }^{76}$ In support of this skepticism, a recent analysis of the CABG Off or On Pump Revascularization Study (CORONARY) ${ }^{77}$ by Garg et al. showed in this interventional trial setting that patients randomized to off-pump coronary artery bypass had 17\% lower rates of AKI ( $250 \%$ increase in serum $\mathrm{Cr}$ ) than those randomized to on-pump bypass, but there was no difference between the two groups in terms of kidney function loss at one year (defined as $220 \%$ loss in estimated GFR). ${ }^{78}$ Interestingly, when the CORONARY trial was analyzed as a prospective cohort, AKI was independently associated with a greater risk of kidney function loss at 1 year (adjusted OR 3.4, 95\% CI 2.7-4.3). ${ }^{78}$ Although this study has been criticized for lack of power due to the relatively modest effect of the off-pump bypass,${ }^{79}$ these data argue that observational studies suffer from residual confounding, especially when only relatively mild cases of AKI—of the type observed in CORONARYare being considered.

Future epidemiological studies designed to address the question whether AKI itself causes longer-term kidney function decline will need to be more rigorous in ascertaining baseline CKD—status including baseline, pre-AKI estimated GFR trajectory (rather than just a static estimated GFR level) which has not been captured in many published studies. ${ }^{39,58,72,73,80}$ Prospective ascertainment of renal function trajectory after AKI would also be a methodological advance over retrospective studies that have had to rely on data collected as part of routine clinical care and the associated risk of bias due to differential ascertainment and missing observations. ${ }^{81}$

\section{Future directions}

One promising avenue may be for future studies to examine the impact of AKI on development or exacerbation of other renal outcomes such as hypertension, which may be a more subtle manifestation of tubular injury ${ }^{82}$ than frank elevations in serum $\mathrm{Cr}$ (since overall GFR may be maintained even with nephron dropout by increases in single nephron GFR ${ }^{83}$ ). Some animal studies of renal ischemia-reperfusion injury have shown that post-ischemic rats develop salt-sensitive hypertension, potentially mediated through alterations in pressure natriuresis. ${ }^{84,85}$ And indeed, a recent study showed that among normotensive individuals, AKI was an independent risk factor for subsequent development of elevated blood pressure. ${ }^{86}$ 
Another potential area of investigation would be to better define the relationship between AKI and other important outcomes common in CKD patients, such as cardiovascular disease events. ${ }^{87}$ Some have suggested that the upsurge of profibrotic and apoptotic factors after an acute episode of inflammation during AKI has deleterious effects on remote organs and that this "uremic memory" enables one episode of AKI to leave an imprint, putting patients at risk for long-term morbidity and mortality. ${ }^{88}$ There is a body of literature about how AKI appears to enhance risk of future CVD events in the setting of cardiac interventions (such as percutaneous or surgical revascularization for coronary artery disease $)^{89,90}$ but data are now emerging in other settings as well ${ }^{1,92}$ and this should be a fruitful area of research in the coming years.

If AKI truly were an important mechanism through which CKD occurs and progresses (i.e., assuming the association between CKD and AKI is not principally due to the effects of CKD on subsequent AKI), the need to understand (and prevent) the causes of AKI would become even more compelling. While the severe cases of AKI (in the setting, for example, of septic shock) may be difficult to prevent, it may be important to focus on milder cases of AKI, many of which occur outside of the context of catastrophic illness.

Finally, the best approach to managing patients who experience an episode of AKI has yet to be defined. ${ }^{93}$ Although some academic medical centers have established specialized "postAKI" clinics, ${ }^{94,95}$ there are scant data to guide clinicians and policy makers. Harel et al. reported that early nephrology follow-up after hospitalization with dialysis-requiring AKI was associated with improved survival, ${ }^{96}$ although no mechanism was provided to explain this observation (i.e., it is not clear what nephrologists were doing differently in terms of medical care compared with non-nephrologists). Notably, early nephrology follow-up was also associated with a higher risk of chronic dialysis, ${ }^{96}$ so it is possible that these results could be explained by discharge physicians triaging patients who are more likely to progress to ESRD to nephrologists and patients who are more likely to die from competing causes away from nephrologists and to primary care or other providers. This type of selection bias is difficult to capture in an observational study that relied mostly on administrative codes to describe study participants.

To conclude, although our understanding of the role of AKI in CKD has progressed considerably over the last decade, much work remains to be done. It appears that AKI is both a cause and a consequence of progressive CKD. Assuming so, any observed relationship between AKI and advancing CKD would be composed of two components: AKI contributing to CKD and CKD contributing to AKI. Discerning the size of these relative components requires detailed epidemiological analyses that can potentially identify the best opportunities to intervene to improve patient outcomes.

\section{Acknowledgments}

Financial Support: RKH was supported by K23DK100468; CYH was supported by K24DK092291, U01DK60902 and U01DK82223. 


\section{References}

1. National Kidney Foundation. K/DOQI Clinical Practice Guidelines for Chronic Kidney Disease: Evaluation, Classification, and Stratification. Am J Kidney Dis. 2002; 39(2 Suppl 1):S1-S266. [PubMed: 11904577]

2. Sarnak MJ, Levey AS, Schoolwerth AC, et al. Kidney disease as a risk factor for development of cardiovascular disease: a statement from the American Heart Association Councils on Kidney in Cardiovascular Disease, High Blood Pressure Research, Clinical Cardiology, and Epidemiology and Prevention. Circulation. 2003; 108(17):2154-2169. [PubMed: 14581387]

3. Go A, Chertow G, Fan D, MuCulloch C, Hsu C. Chronic kidney disease and risks of death, cardiovascular events, and hospitalization. N Engl J Med. 2004; 351:1296-1305. [PubMed: 15385656]

4. Hemmelgarn BR, Manns BJ, Lloyd A, et al. Relation between kidney function, proteinuria, and adverse outcomes. JAMA. 2010; 303(5):423-429. [PubMed: 20124537]

5. Hsu CY, Ordonez JD, Chertow GM, Fan D, McCulloch CE, Go AS. The risk of acute renal failure in patients with chronic kidney disease. Kidney Int. 2008; 74(1):101-107. [PubMed: 18385668]

6. Xue JL, Daniels F, Star RA, et al. Incidence and mortality of acute renal failure in Medicare beneficiaries, 1992 to 2001. J Am Soc Nephrol. 2006; 17(4):1135-1142. [PubMed: 16495381]

7. Waikar SS, Curhan GC, Wald R, McCarthy EP, Chertow GM. Declining mortality in patients with acute renal failure, 1988 to 2002. J Am Soc Nephrol. 2006; 17(4):1143-1150. [PubMed: 16495376]

8. Hsu CY, McCulloch CE, Fan D, Ordonez JD, Chertow GM, Go AS. Community-based incidence of acute renal failure. Kidney Int. 2007; 72(2):208-212. [PubMed: 17507907]

9. Hsu RK, McCulloch CE, Dudley RA, Lo LJ, Hsu CY. Temporal changes in incidence of dialysisrequiring AKI. J Am Soc Nephrol. 2013; 24(1):37-42. [PubMed: 23222124]

10. Wald R, McArthur E, Adhikari NK, et al. Changing incidence and outcomes following dialysisrequiring acute kidney injury among critically ill adults: a population-based cohort study. Am J Kidney Dis. 2015; 65(6):870-877. [PubMed: 25533599]

11. Siew ED, Davenport A. The growth of acute kidney injury: a rising tide or just closer attention to detail? Kidney Int. 2014

12. Hsu RK, McCulloch CE, Heung M, et al. Exploring potential reasons for the temporal trend in dialysis-requiring acute kidney injury in the United States. Clinical journal of the American Society of Nephrology: CJASN. 2016 in press.

13. Okusa MD, Chertow GM, Portilla D. The nexus of acute kidney injury, chronic kidney disease, and World Kidney Day 2009. Clinical journal of the American Society of Nephrology: CJASN. 2009; 4(3):520-522. [PubMed: 19225036]

14. Hsu CY. Where is the epidemic in kidney disease? J Am Soc Nephrol. 2010; 21(10):1607-1611. [PubMed: 20813868]

15. Chawla LS, Kimmel PL. Acute kidney injury and chronic kidney disease: an integrated clinical syndrome. Kidney Int. 2012; 82(5):516-524. [PubMed: 22673882]

16. Chawla LS, Eggers PW, Star RA, Kimmel PL. Acute kidney injury and chronic kidney disease as interconnected syndromes. N Engl J Med. 2014; 371(1):58-66. [PubMed: 24988558]

17. Hsu RK, Hsu CY. Proteinuria and reduced glomerular filtration rate as risk factors for acute kidney injury. Curr Opin Nephrol Hypertens. 2011; 20(3):211-217. [PubMed: 21455065]

18. Huang TM, Wu VC, Young GH, et al. Preoperative proteinuria predicts adverse renal outcomes after coronary artery bypass grafting. J Am Soc Nephrol. 2010; 22:156-163. [PubMed: 21115618]

19. Grams ME, Astor BC, Bash LD, Matsushita K, Wang Y, Coresh J. Albuminuria and estimated glomerular filtration rate independently associate with acute kidney injury. J Am Soc Nephrol. 2010; 21:1757-1764. [PubMed: 20671214]

20. James MT, Hemmelgarn BR, Wiebe N, et al. Glomerular filtration rate, proteinuria, and the incidence and consequences of acute kidney injury: a cohort study. Lancet. 2010; 376(9758):20962103. [PubMed: 21094997] 
21. Gansevoort RT, Matsushita K, van der Velde M, et al. Lower estimated GFR and higher albuminuria are associated with adverse kidney outcomes. A collaborative meta-analysis of general and high-risk population cohorts. Kidney Int. 2011; 80(1):93-104. [PubMed: 21289597]

22. Grams ME, Sang Y, Ballew SH, et al. A Meta-analysis of the association of estimated GFR, albuminuria, age, race, and sex with acute kidney injury. Am J Kidney Dis. 2015; 66(4):591-601. [PubMed: 25943717]

23. James MT, Grams ME, Woodward M, et al. A Meta-analysis of the association of estimated GFR, albuminuria, diabetes mellitus, and hypertension with acute kidney injury. Am J Kidney Dis. 2015; 66(4):602-612. [PubMed: 25975964]

24. Singh P, Rifkin DE, Blantz RC. Chronic kidney disease: an inherent risk factor for acute kidney injury? Clin J Am Soc Nephro. 2010; 5(9):1690-1695.

25. Levin A, Warnock DG, Mehta RL, et al. Improving outcomes from acute kidney injury: report of an initiative. Am J Kidney Dis. 2007; 50(1):1-4. [PubMed: 17591518]

26. Kidney Disease Improving Global Outcomes (KDIGO) Acute Kidney Injury Work Group. KDIGO Clinical Practice Guideline for Acute Kidney Injury. Kidney Int, Suppl. 2012; 2:1-138.

27. Pannu N. Bidirectional relationships between acute kidney injury and chronic kidney disease. Curr Opin Nephrol Hypertens. 2013; 22(3):351-356. [PubMed: 23508059]

28. Coca SG, Cho KC, Hsu CY. Acute kidney injury in the elderly: predisposition to chronic kidney disease and vice versa. Nephron Clinical practice. 2011; 119(Suppl 1):c19-24. [PubMed: 21832852]

29. Venkatachalam MA, Weinberg JM, Kriz W, Bidani AK. Failed Tubule Recovery, AKI-CKD Transition, and Kidney Disease Progression. J Am Soc Nephrol. 2015; 26(8):1765-1776. [PubMed: 25810494]

30. Ferenbach DA, Bonventre JV. Mechanisms of maladaptive repair after AKI leading to accelerated kidney ageing and CKD. Nat Rev Nephrol. 2015; 11(5):264-276. [PubMed: 25643664]

31. Basile DP, Donohoe D, Roethe K, Osborn JL. Renal ischemic injury results in permanent damage to peritubular capillaries and influences long-term function. American journal of physiology. Renal physiology. 2001; 281(5):F887-899. [PubMed: 11592947]

32. Venkatachalam MA, Griffin KA, Lan R, Geng H, Saikumar P, Bidani AK. Acute kidney injury: a springboard for progression in chronic kidney disease. Am J Physiol Renal Physiol. 2010; 298(5):F1078-1094. [PubMed: 20200097]

33. Hou S, Bushinsky D, Wish J, Cohen J, Harrington J. Hospital-acquired renal insufficiency: a prospective study. Am J Med. 1983; 74(2):243-248. [PubMed: 6824004]

34. Nash K, Hafeez A, Hou S. Hospital-acquired renal insufficiency. Am J Kidney Dis. 2002; 39(5): 930-936. [PubMed: 11979336]

35. Mangano CM, Diamondstone LS, Ramsay JG, Aggarwal A, Herskowitz A, Mangano DT. Renal dysfunction after myocardial revascularization: risk factors, adverse outcomes, and hospital resource utilization. The Multicenter Study of Perioperative Ischemia Research Group. Ann Intern Med. 1998; 128(3):194-203. [PubMed: 9454527]

36. Chertow G, Levy E, Hammermeister K, Grover F, Daley J. Independent association between acute renal failure and mortality following cardiac surgery. Am J Med. 1998; 104(4):343-348. [PubMed: 9576407]

37. Newsome BB, Warnock DG, McClellan WM, et al. Long-term risk of mortality and end-stage renal disease among the elderly after small increases in serum creatinine level during hospitalization for acute myocardial infarction. Arch Intern Med. 2008; 168(6):609-616. [PubMed: 18362253]

38. Parikh CR, Coca SG, Wang Y, Masoudi FA, Krumholz HM. Long-term prognosis of acute kidney injury after acute myocardial infarction. Arch Intern Med. 2008; 168(9):987-995. [PubMed: 18474763]

39. Coca SG, Singanamala S, Parikh CR. Chronic kidney disease after acute kidney injury: a systematic review and meta-analysis. Kidney Int. 2012; 81(5):442-448. [PubMed: 22113526]

40. Hsu CY, Chertow GM, McCulloch CE, Fan D, Ordonez JD, Go AS. Nonrecovery of kidney function and death after acute on chronic renal failure. Clinical journal of the American Society of Nephrology: CJASN. 2009; 4(5):891-898. [PubMed: 19406959] 
41. Lo L, Go A, Chertow G, et al. Dialysis-requiring acute renal failure increases the risk of progressive chronic kidney disease. Kidney Int. 2009; 76(8):893-899. [PubMed: 19641480]

42. Choi AI, Li Y, Parikh C, Volberding PA, Shlipak MG. Long-term clinical consequences of acute kidney injury in the HIV-infected. Kidney Int. 2010; 78(5):478-485. [PubMed: 20520594]

43. Weiss AS, Sandmaier BM, Storer B, Storb R, McSweeney PA, Parikh CR. Chronic kidney disease following non-myeloablative hematopoietic cell transplantation. Am J Transplant. 2006; 6(1):8994. [PubMed: 16433761]

44. James MT, Ghali WA, Tonelli M, et al. Acute kidney injury following coronary angiography is associated with a long-term decline in kidney function. Kidney Int. 2010; 78(8):803-809. [PubMed: 20686453]

45. James MT, Ghali WA, Knudtson ML, et al. Associations between acute kidney injury and cardiovascular and renal outcomes after coronary angiography. Circulation. 2011; 123(4):409-416. [PubMed: 21242477]

46. Wald R, Quinn R, Luo J, et al. Chronic dialysis and death among survivors of acute kidney injury requiring dialysis. JAMA. 2009; 302(11):1179-1185. [PubMed: 19755696]

47. Lafrance JP, Djurdjev O, Levin A. Incidence and outcomes of acute kidney injury in a referred chronic kidney disease cohort. Nephrol Dial Transplant. 2010; 25(7):2203-2209. [PubMed: 20124548]

48. Ando M, Ohashi K, Akiyama H, et al. Chronic kidney disease in long-term survivors of myeloablative allogeneic haematopoietic cell transplantation: prevalence and risk factors. Nephrol Dial Transplant. 2010; 25(1):278-282. [PubMed: 19762604]

49. Ishani A, Xue JL, Himmelfarb J, et al. Acute kidney injury increases risk of ESRD among elderly. J Am Soc Nephrol. 2009; 20(1):223-228. [PubMed: 19020007]

50. Ishani A, Nelson D, Clothier B, et al. The magnitude of acute serum creatinine increase after cardiac surgery and the risk of chronic kidney disease, progression of kidney disease, and death. Arch Intern Med. 2011; 171(3):226-233. [PubMed: 21325112]

51. Amdur R, Chawla L, Amodeo S, Kimmel P, Palant C. Outcomes following diagnosis of acute renal failure in U.S. veterans: focus on acute tubular necrosis. Kidney Int. 2009; 76(10):1089-1097. [PubMed: 19741590]

52. Hsu CY. Yes, AKI truly leads to CKD. J Am Soc Nephrol. 2012; 23(6):967-969. [PubMed: 22499588]

53. Lin J, Fernandez H, Shashaty MG, et al. False-Positive Rate of AKI Using Consensus CreatinineBased Criteria. Clin J Am Soc Nephrol. 2015; 10(10):1723-1731. [PubMed: 26336912]

54. Waikar SS, Wald R, Chertow GM, et al. Validity of International Classification of Diseases, Ninth Revision, Clinical Modification Codes for acute renal failure. J Am Soc Nephrol. 2006; 17(6): 1688-1694. [PubMed: 16641149]

55. Vlasschaert ME, Bejaimal SA, Hackam DG, et al. Validity of administrative database coding for kidney disease: a systematic review. Am J Kidney Dis. 2011; 57(1):29-43. [PubMed: 21184918]

56. Grams ME, Plantinga LC, Hedgeman E, et al. Validation of CKD and related conditions in existing data sets: A systematic review. Am J Kidney Dis. 2011; 57(1):44-54. [PubMed: 20692079]

57. Grams ME, Waikar SS, MacMahon B, Whelton S, Ballew SH, Coresh J. Performance and limitations of administrative data in the identification of AKI. Clinical journal of the American Society of Nephrology: CJASN. 2014; 9(4):682-689. [PubMed: 24458075]

58. Wu VC, Huang TM, Lai CF, et al. Acute-on-chronic kidney injury at hospital discharge is associated with long-term dialysis and mortality. Kidney Int. 2011; 80(11):1222-1230. [PubMed: 21832983]

59. Pannu N, James M, Hemmelgarn BR, et al. Modification of outcomes after acute kidney injury by the presence of CKD. Am J Kidney Dis. 2011; 58(2):206-213. [PubMed: 21496979]

60. Mehta RL, Pascual MT, Soroko S, et al. Spectrum of acute renal failure in the intensive care unit: the PICARD experience. Kidney Int. 2004; 66(4):1613-1621. [PubMed: 15458458]

61. Thakar CV, Christianson A, Himmelfarb J, Leonard AC. Acute kidney injury episodes and chronic kidney disease risk in diabetes mellitus. Clinical journal of the American Society of Nephrology: CJASN. 2011; 6(11):2567-2572. [PubMed: 21903988]

62. Siew ED, Parr SK, Abdel-Kader K, et al. Predictors of Recurrent AKI. J Am Soc Nephrol. 2015 
63. Lee P, Johansen KL, Hsu CY. End-stage renal disease preceded by rapid declines in kidney function: a case series. BMC nephrology. 2011; 12(1):5. [PubMed: 21284877]

64. Li L, Astor BC, Lewis J, et al. Longitudinal progression trajectory of GFR among patients with CKD. Am J Kidney Dis. 2012; 59(4):504-512. [PubMed: 22284441]

65. O'Hare AM, Batten A, Burrows NR, et al. Trajectories of kidney function decline in the 2 years before initiation of long-term dialysis. Am J Kidney Dis. 2012; 59(4):513-522. [PubMed: 22305760]

66. Hsu RK, Chai B, Roy JR, et al. Abrupt Decline in Kidney Function Before Initiating Hemodialysis and All-Cause Mortality: The Chronic Renal Insufficiency Cohort (CRIC) Study. Am J Kidney Dis. 2016

67. Mitch WE, Walser M, Buffington GA, Lemann J Jr. A simple method of estimating progression of chronic renal failure. Lancet. 1976; 2(7999):1326-1328. [PubMed: 63803]

68. Mammen C, Al Abbas A, Skippen P, et al. Long-term risk of CKD in children surviving episodes of acute kidney injury in the intensive care unit: a prospective cohort study. Am J Kidney Dis. 2012; 59(4):523-530. [PubMed: 22206744]

69. Chawla LS, Amdur RL, Amodeo S, Kimmel PL, Palant CE. The severity of acute kidney injury predicts progression to chronic kidney disease. Kidney Int. 2011; 79(12):1361-1369. [PubMed: 21430640]

70. Bellomo R, Ronco C, Kellum JA, Mehta RL, Palevsky P. workgroup ADQI. Acute renal failure definition, outcome measures, animal models, fluid therapy and information technology needs: the Second International Consensus Conference of the Acute Dialysis Quality Initiative (ADQI) Group. Crit Care. 2004; 8(4):R204-212. [PubMed: 15312219]

71. Bucaloiu ID, Kirchner HL, Norfolk ER, Hartle JE, Perkins RM. Increased risk of death and de novo chronic kidney disease following reversible acute kidney injury. Kidney Int. 2012; 81(5): 477-485. [PubMed: 22157656]

72. Jones J, Holmen J, De Graauw J, Jovanovich A, Thornton S, Chonchol M. Association of complete recovery from acute kidney injury with incident CKD stage 3 and all-cause mortality. Am J Kidney Dis. 2012; 60(3):402-408. [PubMed: 22541737]

73. Heung M, Steffick DE, Zivin K, et al. Acute kidney injury recovery pattern and subsequent risk of CKD: an analysis of Veterans Health Administration data. Am J Kidney Dis.

74. Liu KD, Lo L, Hsu CY. Some methodological issues in studying the long-term renal sequelae of acute kidney injury. Curr Opin Nephrol Hypertens. 2009; 18(3):241-245. [PubMed: 19318944]

75. Rifkin DE, Coca SG, Kalantar-Zadeh K. Does AKI truly lead to CKD? J Am Soc Nephrol. 2012; 23(6):979-984. [PubMed: 22460531]

76. Coca SG. Is it AKI or nonrecovery of renal function that is important for long-term outcomes? Clinical journal of the American Society of Nephrology: CJASN. 2013; 8(2):173-176. [PubMed: 23307878]

77. Lamy A, Devereaux PJ, Prabhakaran D, et al. Off-pump or on-pump coronary-artery bypass grafting at 30 days. N Engl J Med. 2012; 366(16):1489-1497. [PubMed: 22449296]

78. Garg AX, Devereaux PJ, Yusuf S, et al. Kidney function after off-pump or on-pump coronary artery bypass graft surgery: a randomized clinical trial. JAMA. 2014; 311(21):2191-2198. [PubMed: 24886787]

79. Grams ME, Sang Y, Matsushita K. Does acute kidney injury cause longer-term kidney function decline? Am J Kidney Dis. 2015; 65(1):12-14. [PubMed: 25201022]

80. Rydén L, Sartipy U, Evans M, Holzmann MJ. Acute kidney injury after coronary artery bypass grafting and long-term risk of end-stage renal disease. Circulation. 2014; 130(23):2005-2011. [PubMed: 25239439]

81. Go AS, Parikh CR, Ikizler TA, et al. The assessment, serial evaluation, and subsequent sequelae of acute kidney injury (ASSESS-AKI) study: design and methods. BMC nephrology. 2010; 11:22. [PubMed: 20799966]

82. Johnson RJ, Herrera-Acosta J, Schreiner GF, Rodriguez-Iturbe B. Subtle acquired renal injury as a mechanism of salt-sensitive hypertension. N Engl J Med. 2002; 346(12):913-923. [PubMed: 11907292] 
83. Finn WF. Enhanced recovery from postischemic acute renal failure. Micropuncture studies in the rat. Circ Res. 1980; 46(3):440-448. [PubMed: 7357698]

84. Spurgeon-Pechman KR, Donohoe DL, Mattson DL, Lund H, James L, Basile DP. Recovery from acute renal failure predisposes hypertension and secondary renal disease in response to elevated sodium. American journal of physiology. Renal physiology. 2007; 293(1):F269-278. [PubMed: 17507599]

85. Pechman KR, De Miguel C, Lund H, Leonard EC, Basile DP, Mattson DL. Recovery from renal ischemia-reperfusion injury is associated with altered renal hemodynamics, blunted pressure natriuresis, and sodium-sensitive hypertension. Am J Physiol Regul Integr Comp Physiol. 2009; 297(5):R1358-1363. [PubMed: 19710386]

86. Hsu CY, Hsu RK, Yang J, Ordonez JD, Zheng S, Go AS. Elevated blood pressure after acute kidney injury. J Am Soc Nephrol. 2015 ePub July 1, 2015.

87. Hsu CY, Liu KD. Cardiovascular events after AKI: a new dimension. J Am Soc Nephrol. 2014; 25(3):425-427. [PubMed: 24503240]

88. Golestaneh L, Melamed ML, Hostetter TH. Uremic memory: the role of acute kidney injury in long-term outcomes. Kidney Int. 2009; 76(8):813-814. [PubMed: 19789540]

89. James MT, Samuel SM, Manning MA, et al. Contrast-induced acute kidney injury and risk of adverse clinical outcomes after coronary angiography a systematic review and meta-analysis. CircCardiovasc Inte. 2013; 6(1):37.

90. Corredor C, Thomson R, Al-Subaie N. Long-term consequences of acute kidney injury after cardiac surgery: a systematic review and meta-analysis. J Cardiothorac Vasc Anesth.

91. Wu VC, Wu PC, Wu CH, et al. The impact of acute kidney injury on the long-term risk of stroke. Journal of the American Heart Association. 2014; 3(4)

92. Wu VC, Wu CH, Huang TM, et al. Long-term risk of coronary events after AKI. J Am Soc Nephrol. 2014; 25(3):595-605. [PubMed: 24503241]

93. Goldstein SL, Jaber BL, Faubel S, Chawla LS. AKI transition of care: a potential opportunity to detect and prevent CKD. Clinical journal of the American Society of Nephrology: CJASN. 2013; 8(3):476-483. [PubMed: 23471414]

94. Silver S, Goldstein S, Harel Z, et al. Ambulatory care after acute kidney injury: an opportunity to improve patient outcomes. Can J Kidney Health Dis. 2015; 2(1):36. [PubMed: 26445676]

95. Silver SA, Harel Z, Harvey A, et al. Improving care after acute kidney injury: a prospective time series study. Nephron. 2015; 131(1):43-50. [PubMed: 26329832]

96. Harel Z, Wald R, Bargman JM, et al. Nephrologist follow-up improves all-cause mortality of severe acute kidney injury survivors. Kidney Int. 2013; 83(5):901-908. [PubMed: 23325077] 

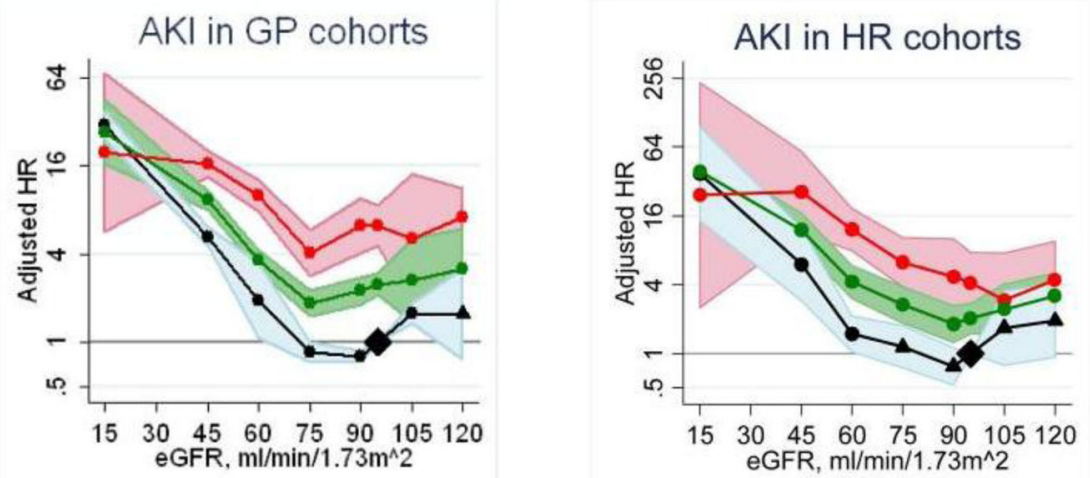

FIGURE 1. Pooled adjusted hazard ratios for acute kidney injury according to estimated GFR and albuminuria, reproduced with permission from Gansevoort et al. ${ }^{21}$

Hazard ratios are adjusted for age, sex, and cardiovascular risk factors. Reference category is estimated GFR $95 \mathrm{ml} / \mathrm{min} / 1.73 \mathrm{~m}^{2}$ plus albumin-to-creatinine ratio $5 \mathrm{mg} / \mathrm{g}$ or dipstick negative or trace. Left panel shows result for general population cohorts, and right panel for high-risk cohorts. Dots represent statistical significance, triangles represent nonsignificance, and shaded areas are $95 \%$ confidence intervals. Black lines and blue shading represent an albumin-to-creatinine ratio of $<30 \mathrm{mg} / \mathrm{g}$ or dipstick negative or trace; green lines and green shading represent an albumin-to-creatinine ratio 30-299 mg/g or dipstick 1+; red lines and red shading represent an albumin-to-creatinine ratio $2300 \mathrm{mg} / \mathrm{g}$ or dipstick $\geq 2+$.

HR, hazard ratio; AKI, acute kidney injury; GP cohorts, general population cohorts; HR cohorts, high-risk cohorts; eGFR, estimated glomerular filtration rate. 


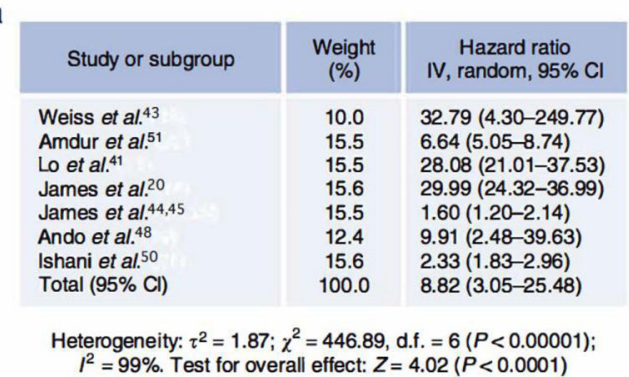

b

\begin{tabular}{|c|c|c|}
\hline Study or subgroup & $\begin{array}{l}\text { Weight } \\
(\%)\end{array}$ & $\begin{array}{c}\text { Hazard ratio } \\
\text { IV, random, } 95 \% \mathrm{CI}\end{array}$ \\
\hline $\begin{array}{l}\text { Newsome et al. }{ }^{37} \\
\text { Ishani et al.49 } \\
\text { Wald et al. }{ }^{46} \\
\text { Hsu et al. }{ }^{40} \\
\text { James et al. }{ }^{44,45} \\
\text { Lafrance et al }{ }^{47} \\
\text { Choi et al. }{ }^{42} \\
\text { Total }(95 \% \mathrm{Cl})\end{array}$ & $\begin{array}{r}15.0 \\
14.8 \\
14.9 \\
13.5 \\
12.5 \\
15.0 \\
14.4 \\
100.0\end{array}$ & $\begin{array}{l}3.26(2.87-3.70) \\
12.99(10.57-15.96) \\
3.22(2.70-3.85) \\
1.47(0.95-2.28) \\
4.15(2.32-7.41) \\
2.33(2.08-2.61) \\
1.37(1.02-1.84) \\
3.10(1.91-5.03)\end{array}$ \\
\hline
\end{tabular}

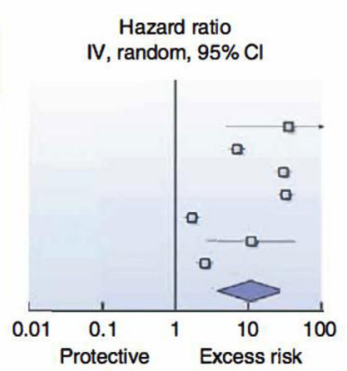

Hazard ratio

IV, random, $95 \% \mathrm{Cl}$

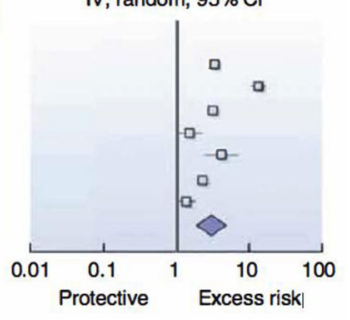

FIGURE 2. Meta-analysis of chronic kidney disease (CKD) and end-stage renal disease (ESRD) associated with acute kidney injury (AKI), reproduced with permission from Coca et al. ${ }^{39}$ (a) Pooled adjusted hazard ratios for CKD after AKI. (b) Pooled adjusted hazard ratios for ESRD after AKI. 


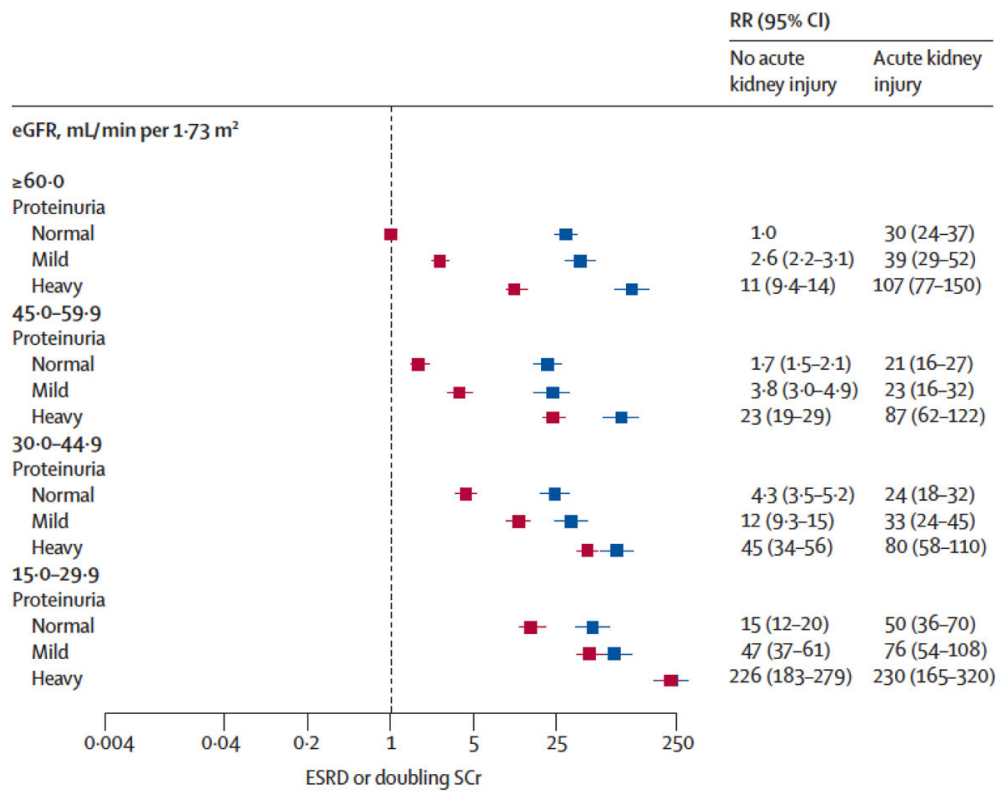

FIGURE 3. Rate ratios of the composite outcome of end-stage renal disease or doubling of serum creatinine after acute kidney injury (AKI) by baseline kidney function and proteinuria, reproduced with permission by James, et al. ${ }^{20}$

Blue squares and horizontal bars represent point estimates and 95\% CIs respectively for rate ratios of participants who had AKI for various values of eGFR and proteinuria. Red squares and horizontal bars similarly represent the point estimates and 95\% CIs for participants who did not have AKI. The referent group for all rate ratios are participants who did not have AKI, and had normal proteinuria and eGFR $260 \mathrm{ml} / \mathrm{min} / 1.73 \mathrm{~m}^{2}$.

$\mathrm{RR}$, rate ratio; eGFR, estimated glomerular filtration rate; ESRD, end-stage renal disease. 


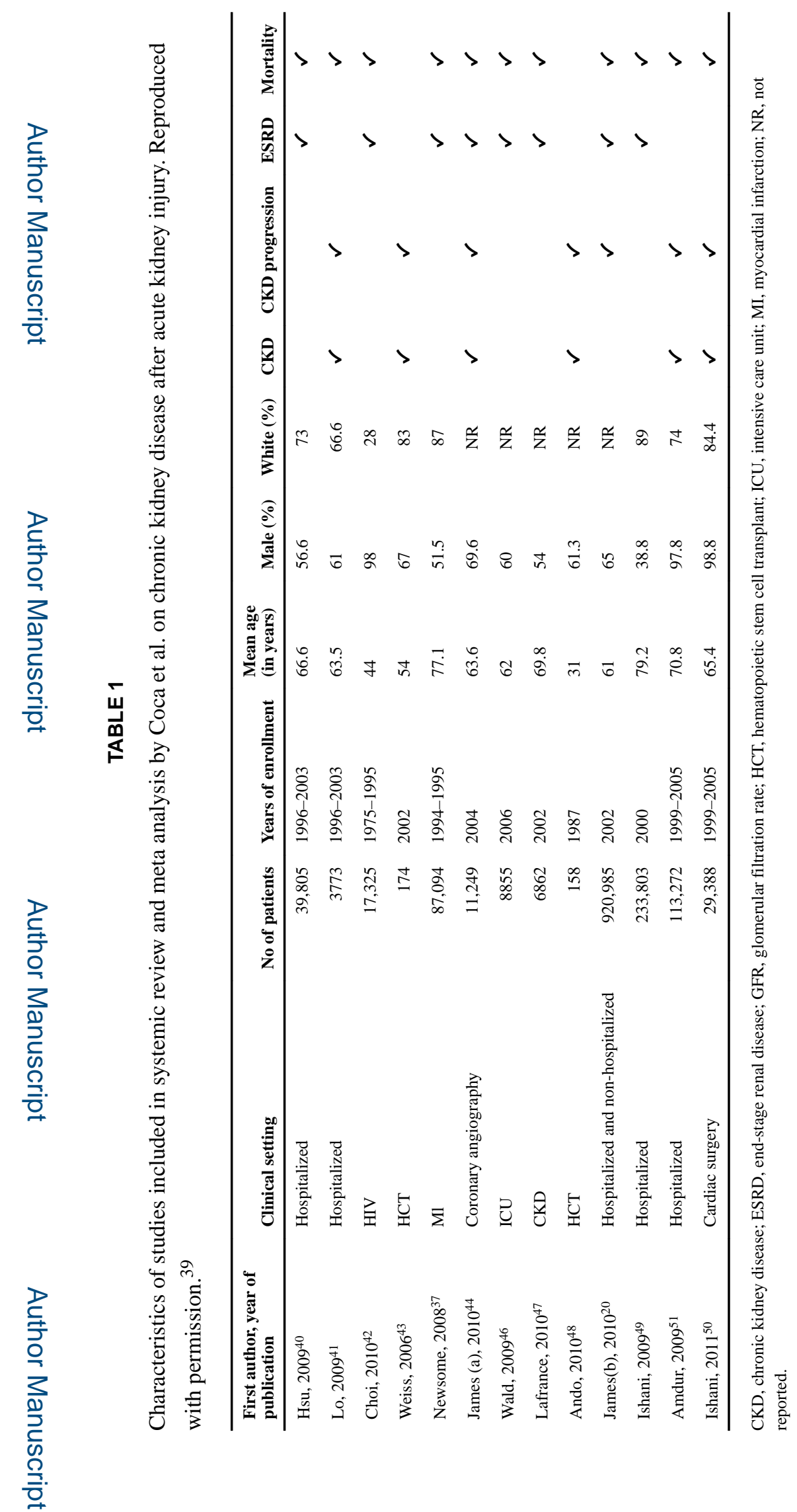

Semin Nephrol. Author manuscript; available in PMC 2017 July 01. 